\title{
Christa Dürscheid
}

Die verbalen Kasus des Deutschen
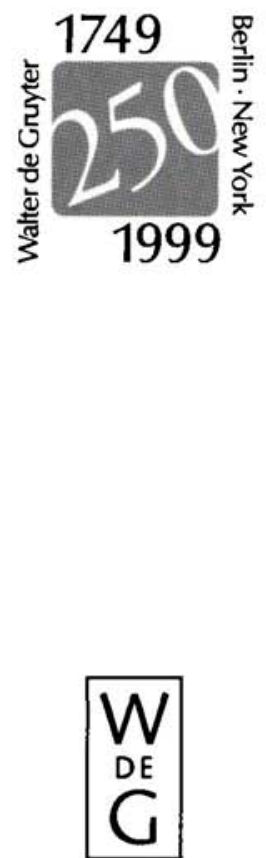


\title{
Studia Linguistica Germanica
}

\author{
Herausgegeben \\ von \\ Stefan Sonderegger \\ und \\ Oskar Reichmann
}

53

Walter de Gruyter - Berlin - New York 1999 
Christa Dürscheid

\section{Die verbalen Kasus des Deutschen}

Untersuchungen zur Syntax, Semantik und Perspektive

Walter de Gruyter - Berlin - New York 1999 


\title{
Als Habilitationsschrift auf Empfehlung \\ der Philosophischen Fakultät der Universität zu Köln \\ gedruckt mit Unterstützung der Deutschen Forschungsgemeinschaft
}

\author{
(0) Gedruckt auf säurefreiem Papier, \\ das die US-ANSI-Norm über Haltbarkeit erfüllt.
}

Die Deutsche Bibliothek - CIP-Einheitsaufnahme

\section{Dürscheid, Christa:}

Die verbalen Kasus des Deutschen : Untersuchungen zur Syntax, Semantik und Perspektive / Christa Dürscheid. - Berlin ; New York : de Gruyter, 1999

(Studia linguistica Germanica ; 53)

Zugl.: Köln, Univ., Habil.-Schr., 1998

ISBN 3-11-016492-2

(C) Copyright 1999 by Walter de Gruyter GmbH \& Co. KG, D-10785 Berlin

Dieses Werk einschließlich aller seiner Teile ist urheberrechtlich geschützt. Jede Verwertung außerhalb der engen Grenzen des Urheberrechtsgesetzes ist ohne Zustimmung des Verlages unzulässig und strafbar. Das gilt insbesondere für Vervielfältigungen, Übersetzungen, Mikroverfilmungen und die Einspeicherung und Verarbeitung in elektronischen Systemen.

$$
\text { Printed in Germany }
$$

Druck: Werner Hildebrand, Berlin

Buchbinderische Verarbeitung: Lüderitz \& Bauer-GmbH, Berlin 